Voix et Images

\title{
Social Realism in the French-Canadian Novel de Ben-Zion Shek ou notre roman entre les faits et la fiction
}

\section{Joseph Bonenfant}

Volume 4, numéro 3, avril 1979

Louis-Philippe Hébert

URI : https://id.erudit.org/iderudit/200180ar

DOI : https://doi.org/10.7202/200180ar

Aller au sommaire du numéro

Éditeur(s)

Les Presses de l'Université du Québec

\section{ISSN}

0318-9201 (imprimé)

1705-933X (numérique)

Découvrir la revue

Citer ce compte rendu

Bonenfant, J. (1979). Compte rendu de [Social Realism in the French-Canadian Novel de Ben-Zion Shek ou notre roman entre les faits et la fiction]. Voix et Images, 4(3), 545-547. https://doi.org/10.7202/200180ar d'utilisation que vous pouvez consulter en ligne. 


\section{Social Realism in the French-Canadian Novel ${ }^{1}$ de Ben-Zion Shek ou notre roman entre les faits et la fiction}

A première vue, le titre peut effrayer. On écarte spontanément le "réalisme socialiste" pour le laisser à d'autres. Quant à " réalisme social", l'expression ne donne pas lieu à une entente simple. De toutes manières, elle n'est pas dangereuse, ou fausse, ou trop compliquée. $A$ la fin de la conclusion, l'auteur, citant Gilles Vigneault, définit l'essence du réalisme social comme la relation de symbiose qui s'établit entre l'artiste créateur et les petites gens ainsi qu'avec la vie de tous les jours. Et de citer “ les gens de mon pays". Nous sommes rassurés.

Cette fin bien enlevée éclaire rétrospectivement tout le livre du professeur de l'université de Toronto. Ben Shek a eu le souci, dès l'ouverture de son étude, d'invoquer des romanciers réalistes français, comme Zola et, à un moindre degré, Balzac et Flaubert. Le souci également de s'entourer de modèles, comme Goldmann et Falardeau, dont on sent davantage la présence comme guides que comme autorités. De Goldmann, il retient les concepts de "compréhension" (description précise d'une structure signifiante) et d' "explication" (insertion de cette structure dans une structure génétique plus vaste). De Jacques Allard, il cite une formule heureuse: "Le texte dans l'histoire et l'histoire dans le texte." Ainsi balisée, la recherche étudie le roman comme fiction et met en lumière ses contours et ses contenus économico-socio-politiques. 
Pragmatiquement, pour Shek, le réalisme est :une approche esthétique qui décrit la vie quotidienne dans sés dimensions sociales et. historiques, même les plus précaires et les plus miséreuses. Plus d'une fois, l'auteur précise qu'il ne veut pas priver. les cuvres de leur individualité. Exemple: "Without detriment to the rich imagination and personal creativity of the writers. ' Une fois le projet défini, les. références données et les nuances apportées, le livre prend force dans la lecture, se distribue sur quatre parties bien structurées, lesquelles sont les lieux d'unité de dix chapitres.

Les grands titres sont: "The Background" (économique, social, politique et littéraire), "The Working-class Family, the Depression and the War", "The White-collar Worker" et "Opposition and Revolt". Les analyses les plus fouillées sont consacrées à Gabrielle Roy et à Roger Lemelin; la période étudiée couvre les années 1944 à 1969. Un aspect passionnant de ce livre consiste dans le regroupement de romans sous des titres variés et complémentaires, comme le Feu dans l'amiante, les Pédagogues, les Vivants, les morts et les autres et la Bagarre sous le titre de Industrial and Social Conflict; de Cotnoir, de la Corde au cou, d'Ethel et le terroriste et du Cassé, sous le titre de Crime and Anti-social Acts et finalement, de la Quête d'identité, pour Godbout, Aquin, certains Bessette et Ducharme. Ainsi rapprochés, ces romans montrent plus leurs différences que leurs ressemblances; leurs différences dans l'ordre fictif, leurs resșemblances dans l'ordre social. L'illusion de réalité ressort de l'un et l'autre ordre.

Shek offre une synthèse nouvelle de notre roman de la vie urbaine et de l'ère industrielle; son livre prendra très avantageusement place à côté des études de Falardeau, de Robidoux et de Renaud, de Marc Gagné, de Claude Racine, de Maurice Lemire et d'Antoine Sirois. II décrit certes une évolution historiquement datée, celle de notre société qui de rurale et d'agricole devient urbaine et industrialisée. Mais il va plus loin. II s'attache à plus de complexité. Ben Shek excelle à mettrè en. relations d'équivalences des caractères spécifiques de personnages et de situations. S'il préserve l'individu dans le “sujet transindividuel "t le privé dans le «sujet collectif ", c'est qu'il est attentif à la fiction. II n'oublie pas que le roman est une création gratuite (et nécessaire) dont la force dépend de l'autonomie. Donc, la représentation est propre à l'écrivain. Mais la représentation renvoie à la société: II y a liberté et non-liberté. L'œuvre reflète nécessairement une société, une histoire économique et politique; mais ses moyens et ses "pompes" sont inaliénablement une production largement imprévisible. réellement novatrice et individuellement importante. Autrement dit, rien dans l'œuvre romanesque qui ne relève autant de l'idéologie que du travail, du collectif que du privé. 
Nous sommes habitués à tant de lectures de l'ordre fictif du roman qu'une lecture de son ordre réaliste, c'est-à-dire économique, social et politique, nous étonne facilement. Shek a bien marié les analyses interne et externe, les parts subjective et objective, les aspects esthétiques et idéologiques. Quand cette sorte d'analyse est réussie, comme je crois qu'elle l'est ici, on la trouve naturelle; en réalité, elle ne l'est pas autant qu'on pense. II n'était pas facile de considérer en même temps l'univers imaginaire et la société réelle que chaque roman construit et déconstruit. Pour gagner ce pari, Ben Shek a constamment lu nos romans à partir de ce double foyer, de cette double articulation. Pour ôter toute ambiguïté et marquer son intention, il a mis "Social Realism» dans le titre. Or, malgré la référence, l'étude n'est pas exclusivement goldmannienne. Le dire, c'est rendre justice à ce livre important et saluer une incontestable réussite.

Joseph Bonenfant

1. Montréal, Harvest House, 1977, 326 p. 